\title{
Chronic pulmonary paracoccidioidomycosis in an AIDS patient and Mycobacterium gordonae as confounding factor
}

Authors

Érique José Peixoto de

Miranda ${ }^{1}$

Luiz Guilherme

Gonçalves ${ }^{2}$

Francisco Oscar de

Siqueira França ${ }^{3}$

${ }^{1}$ Graduation in Medicine

- Resident Physician,

Department of Infectious

Diseases, School of

Medicine, Universidade de

São Paulo - USP, São Paulo,

Brazil

${ }^{2}$ Resident Physician,

Infectious Diseases

Department, School of

Medicine, USP, São Paulo,

Brazil

${ }^{3}$ Full Professor and

Assistant Physician,

Department of Infectious

Diseases, School of

Medicine, USP, São Paulo,

Brazil

Submitted on: 09/25/2010

Approved on: 09/25/2010

Correspondence to:

Érique José Peixoto de Miranda

Av. Enéas de Carvalho

Aguiar, 225

Cerqueira Cesar

05403-000 São Paulo,

Brazil

erique@fcm.unicamp.br

We declare no conflict of interest.
Paracoccidioidomycosis is an endemic fungal infection restricted geographically to South and Central America. The incidence in patients with HIV/AIDS was $1.5 \%$, higher than in the general population $(0.02 \%)$.

We report a case of a 47-year-old man presented with five months of cough with yellow sputum, weight loss of $5 \mathrm{~kg}$, daily evening fever, ranging from $38^{\circ} \mathrm{C}$ to $39^{\circ} \mathrm{C}$, malaise, anorexia, dyspnea on exertion and night sweats. He reported diagnosis of AIDS four years ago (initial $\mathrm{CD} 4=86$ cells $/ \mathrm{mm}^{3}$ ). No previous opportunistic diseases and reported use of combination zidovudine-lamivudine and lopinavir boosted with ritonavir, both twice a day, during four years, but discontinued the use of drugs in the last six months on his own. During this period, his CD4 count decreased from 400 cells $/ \mathrm{mm}^{3}$ to 160 cells $/ \mathrm{mm}^{3}$. He reported a history of 60 packyears smoking since the age of 15 years.

Physical examination was normal except for enlarged liver $3 \mathrm{~cm}$ from the costal margin in the midclavicular line, marked clubbed fingers and watch-glass nails. His arterial blood gases on room air was $\mathrm{pH}$ : 7.46; $\mathrm{pO}_{2}: 131 \mathrm{mmHg} ; \mathrm{pCO}_{2}$ : $29.8 \mathrm{mmHg} ; \mathrm{HCO}_{3}: 21.1 \mathrm{mEq} / \mathrm{L} ; \mathrm{SO}_{2}: 99.1 \%$; base excess (BE): $-1.4 \mathrm{mmol} / \mathrm{L}$; serum sodium, $134 \mathrm{mEq} / \mathrm{L}$; serum potassium, $3.7 \mathrm{mEq} / \mathrm{L}$; lactate dehydrogenase (LDH), 340 IU/L; C-reactive protein (CRP), $11.8 \mathrm{mg} / \mathrm{L}$; hemoglobin, $12.3 \mathrm{~g} / \mathrm{dL} ; \mathrm{Ht}$, $38 \%$; leukocytes, $2,810 / \mathrm{mL}$; 1,600 neutrophils (55.9\%); 800 lymphocytes (29.9\%) and 300 monocytes (11.4\%). Platelets were $134.000 / \mathrm{mL}$. Aspartate transaminase (AST) was $15 \mathrm{IU} / \mathrm{L}$ and alanine transaminase (ALT) was $11 \mathrm{IU} / \mathrm{L}$.

During hospitalization, antiretrovirals and primary prophylaxis for PCP with trimetho$\mathrm{prim} / \mathrm{sulfamethoxazole}$ were reintroduced and the patient reported mild improvement of symptoms and resolution of fever.

Mycobacterium gordonae was isolated from sputum, tuberculin purified protein derivative (PPD) intradermal test (RT23, 2 UI, 0,1 UmL) of zero millimeter and chest x-ray PA and lateral view presented superior and inferior left lobe and inferior right lobe cotton-like densities without air bronchogram, and classical "butterfly wing" pattern. Chest computed tomography (CT) scan revealed bronchial diffuse wall thickening, consolidations and nodules with spiky irregular borders, with air bronchograms, measuring between 0.6 and $4.7 \mathrm{~cm}$ in all lung lobes and areas of centrilobular emphysema.

A transparietal CT-guided biopsy of the nodule located in the posterior segment of left lower lobe revealed granulomatous inflammatory reaction with large number of the characteristic "pilot wheel" of Paracoccidioides brasiliensis. Multiple budding yeasts (blastoconidia) and demonstration by Grocott staining. Cultures in Sabouraud dextrose agar obtained from this material turned out negative.

This case is a chronic adult form of paracoccidioidomycosis, which accounts for $80-90 \%$ of cases and represents endogenous reactivation years after initial contact with the fungus. However, this is not the most frequent form in immunosupressed patient. Within the largest Brazilian cohort of paracoccidioidomycosis $(3,744$ patients) $53(1.4 \%)$ patients were coinfected with HIV (Pbm-HIV), during 1986-2004. ${ }^{1}$ Patients coinfected with HIV were younger (33.5 \pm 8.9 years; range $=16-57$ years), $42 / 53$ smoked $(79.2 \%)$ and were less involved in agricultural occupations; $83.7 \%$ had CD4+ cell count $<200$ cells/ $\mu \mathrm{L} .{ }^{1}$ As in the case presented, only $15 / 53$ of coinfected subjects were taking antiretroviral drugs, 10 of whom were taking trimethoprim-sulfamethoxazole for prophylaxis against Pneumocystis jiroveci infection.

Mycobacterium gordonae is found as a saprophytic microorganism in sputum, gastric lavage and urine obtained from healthy hosts and is associated to hospital pseudo-outbreaks. It is the least pathogenic mycobacteria. ${ }^{2,3}$ Diagnostic criteria of infection include fever for more 
than two weeks, pulmonary infiltrates at chest radiograph and more than four respiratory samples positive for Mycobacterium gordonae with high colony counts of (> 100), histopathological confirmation, evidence of dissemination (sepsis, infection of the cornea, peritoneum, urine and synovial fluid) and CD $4<50$ cells $/ \mu \mathrm{L} .{ }^{2}$ This case did not meet these criteria.

In a case series clinical specimens obtained from $15 \mathrm{HIV}$ negative patients with Mycobacterium gordonae ruled out the pathogenicity of this agent. ${ }^{4}$ Chest $\mathrm{x}$-ray abnormality seen in nine patients was attributed to the underlying disease. Twelve of the 15 patients were followed-up for 12 months without recurrence of positive cultures. In another study of $21 \mathrm{HIV}$ infected patients, 17 had progressed to AIDS, all presented fever for more than two weeks and $95.24 \%$ (20/21) had fever. Mean age was 39 years (range: 26-52), 11 were white; three blacks and seven Hispanics. Male/female ratio was 18:3, mean CD 4 count was 56 cells $/ \mu \mathrm{L}$ (ranging from 2 cells/ $\mu \mathrm{L}$ to 203 cells $/ \mu \mathrm{L}$ ). Two cases had disseminated disease. ${ }^{4}$

We conclude that paracoccidiodomycosis, regardless of the form, must be considered in HIV-infected persons in countries where this mycosis is endemic.

[Braz J Infect Dis 2011;15(1):92-93]@Elsevier Editora Ltda.

\section{REFERENCES}

1. Morejón KM, Machado AA, Martinez R. Paracoccidioidomycosis in patients infected with and not infected with human immunodeficiency virus: a case-control study. Am J Trop Med Hyg. 2009; 80(3):359-66.

2. Management of opportunist mycobacterial infections: Joint Tuberculosis Committee Guidelines 1999. Subcommittee of the Joint Tuberculosis Commmitte of the British Thoracic Society. Thorax 2000; 55(3):210-8.

3. Weinberger M, Berg SL, Feuerstein IM. Disseminated Infection with Mycobacterium gordonae: Report of a Case and Critical Review of the Literature. Clin Infect Dis. 1992; 14(6):1229-39.

4. Lessnau KD, Milanese S, Talavera W. Mycobacterium gordonae: a treatable disease in HIV-positive patients. Chest 1993; 104:1779-85. 